\title{
ENTREVISTA
}

\section{ESTUDOS E PERSPECTIVAS DE PESQUISAS EM RELIGIÃO NA AMAZÔNIA, ENTREVISTA COM KARLA DENISE MARTINS}

\author{
Marcos Vinicius de Freitas Reis ${ }^{1}$ \\ José Galdêncio da Silva²
}

Karla Denise Martins é, seguramente, umas das mais influentes estudiosas da religião na Amazônia. Historiadora de formação, com mestrado e doutorado desenvolvido na Universidade Estadual de Campinas (UNICAMP) com ênfase em História Cultural. Atualmente desempenha funções como professora na pós graduação do curso de História da Universidade Federal de Viçosa (UFV), no programa: Patrimônio Cultural, Paisagens e Cidadania; Seus interesses de pesquisa concentra-se em: Religião e Patrimônio, Métodos e Técnicas de Pesquisa, História da igreja católica e Pensamento Clerical.

Suas contribuições são vultosas e ricas para o estudo e compreensão do universo religioso na Amazônia brasileira, mostrando assim seu amadurecimento intelectual, mas, alguns traços são comuns e fundamentais em seus escritos. Em primeiro lugar a compreensão do papel do catolicismo na formação da identidade civilizadora da Amazônia oitocentista e o desemborca das relações político-sociais no contexto amazônico sob a égide imperial. Por fim, suas reflexões voltaram-se para apreensão do patrimônio religioso.

De certa forma, todos os temas que acompanharam/acompanham seu maturar intelectual e acadêmico irão ser abordados nesta entrevista que se segue. Nela buscamos, em um movimento ousado, apontar à uma só vez, os temas centrais dos escritos da Karla Denise e direcionar novos caminhos e problemáticas para pesquisa em religião para aqueles (a) que pretendem adentrar neste campo de pesquisa.

\footnotetext{
${ }^{1}$ Doutor em Sociologia pela Universidade Federal de São Carlos. Docente do Curso de Mestrado Profissional Ensino de História UNIFAP. Docente do Curso de Graduação em Relações Internacionais e História da Universidade Federal do Amapá (UNIFAP). Docente da Especialização Estudos Culturais e Políticas Públicas. Possui graduação em História pela Universidade Federal de Uberlândia (UFU) e mestrado em Ciência Política pela Universidade Federal de São Carlos (UFSCar). Membro do Núcleo de Estudos de Religião, Economia e Política (NEREP). Pesquisador do Observatório em Direitos Humanos da Amazônia (OBADH). Membro do grupo de pesquisa Estudos Interdisciplinares em Cultura e Políticas Públicas (CNPq/UNIFAP). Líder do Centro de Estudos Políticos, Religião e Sociedade na Amazônia (CEPRES). Tesoureiro da Associação Nacional de Historiadores Sessão Amapá (ANPUH AP). Filiado a Associação Brasileira de Historiadores da Religião (ABHR). Coordenador da ABHR Região Norte. Tem experiência na área de Sociologia, com ênfase em Sociologia da Religião, atuando principalmente nos seguintes temas: Renovação Carismática Católica, Pentecostalismo, Representação Política, Religião e Política, Diversidade Religiosa na Amazônia, religiosidade amapaense, Catolicismo e Protestantismo na Amazônia. E-mail: marcosvinicius5@yahoo.com.br

${ }^{2}$ Bolsista PIBIC/Cnpq, membro e pesquisador do Centro de Estudos, Políticos, Religião e Sociedade (CEPRES). Colaborador voluntario do Laboratório de Estudos da História Social do Trabalho na Amazônia (LEHSTAM) e do Centro de Memória, Documentação Histórica e Arquivo-CEMEDHARQ. E-mail: galdenciosilva320@hotmail.com
} 
*Professora Karla Denise, como os estudos de religião foram inseridos na sua carreira acadêmica e profissional e quais aos caminhos a serem percorridos por aquele(a) que se propõe a enveredar pesquisas no campo religioso e em especial para com as religiões na Amazônia?

Karla Denise: Eu tinha pouca idade quando fui semi-interna em um Colégio tradicional para educandas, Colégio Berço de Belém na cidade de Belém do Pará nos idos de 1970. Após a experiência com a educação infantil, quase ingressei no ensino fundamental da mesma Escola por ter ganho uma bolsa de melhor desempenho no ano de 1980, mas acabei não utilizando o benefício por uma viagem repentina ao Rio de Janeiro. Desde cedo interessei-me por histórias religiosas, vida de santos e estudos cristãos-bíblicos, seja na Escola Católica dos Capuchinhos, seja no Colégio Santo António aonde frequentava em eventos quando criança. Percorri diversas religiões depois disso, não como pesquisadora, mas como alguém que sondava esse terreno, visitei templos dos mórmons, protestantes, católicos, todo o tipo de crença e, por fim espíritas, quando decidi largar tudo isso e fazer meu próprio percurso. Na universidade, quando entrei no curso de História, continuava a pesquisar sozinha todos os livros que diziam algo sobre religião ou coisas do tipo, li de tudo, mas a busca continuava e por um episódio inexplicável aos 18 anos, escolhi pesquisar a vida de um Bispo (D. Macedo Costa que atuou na Diocese do Pará entre 1861 e 1890), foi quando precisei escrever textos acadêmicos. Eu acredito que os campos à pesquisa são enormes basta dizer que no Brasil a população católica declarada em 2010 com as estatísticas do IBGE é de 64,63. embora perdendo fiéis (isso porque em 1970 91,8\% se declaravam católicos), a população dessa Igreja ainda é imensa, mesmo com todo o processo de secularização, transformações e abalos como os escândalos sexuais que a todo momento são noticiados na mídia. As Religiões com "R" maiúsculo são mais que sistemas de crenças, são indústrias aonde se fabrica respostas para os fragilizados, desesperados, deprimidos e mesmo para os pobres materialmente. Veja que não estou falando de sentimento religioso, mas de RELIGIÃO como instituição e máquina orgânica. É preciso discernir bem e ter certa sagacidade para reconhecer separar o "joio do trigo". Meu encorajamento aos estudos religiosos se dá no sentido de buscar abordagens críticas, mediadas por métodos de pesquisa (alguns próprios confesso) e empatia, ou seja, não encorajo ou abandono às crenças à escrita de um texto acadêmico, embora ensine meus alunos a separar na sua escrita a paixão que sentem por seus "objetos". Recentemente participei de uma banca aonde os verbos na

\footnotetext{
${ }^{3}$ Segundo os dados do IBGE, já os católicos passaram de 73,6\% em 2000 para 64,6\% em 2010.
} 
dissertação do aluno eram temerosos às afirmações do conteúdo que, na crença dele, sei porque o conheço, são reais e factíveis. Mas, no espaço acadêmico é preciso ser "neutro", demonstrar "dados" e sugerir "provas". O processo de pesquisa, portanto, não pode ser dissociado do que acreditamos, do que estamos aptos a reconhecer como prováveis, embora sejamos forçados ao esquema da cartilha já pronta e performática ao qual o universo acadêmico precisa seguir. Toda essa exposição é um tanto embaraçosa, por vezes, forte, porém, é o que percebo e é o que presencio nestes quase 20 anos de profissão. Estamos condenados ao formato de pensamento herdado da Revolução Científica e dos passos que as Ciências Humanas optaram no século XIX. Uso métodos ainda como todo mundo acadêmico: prosopografia, pesquisa de arquivo, métodos comparativos, leitura simultânea bibliografia e documento, base de dados etc. Mas, quando construo o texto, é a mim que construo. Enfim, a História das Religiões no Brasil caminhou por muitas correntes, influenciadas pelo positivismo no início do século passado, pela teologia da libertação (na década de 1970) e pela Escola dos Annales ${ }^{4}$ a partir dos anos de 1980 no Brasil, com todo o tipo de método e abordagem aplicado aos trabalhos acadêmicos. Ainda continuamos nesse caminho com alguns avanços e não mudou muita coisa, a não ser os temas, violência e religião, sexualidade e religião, tolerância e religião, gênero e religião etc. Sai da Amazônia em 2001, fui morar no centro sul, já não sei mais como andam as pesquisas nas universidades daquela região, mas até onde sei, as grandes questões que são suscitadas em eventos e trabalhos acadêmicos no centro-sul são tratadas em todo o país com algumas exceções talvez, mas vejamos, essa é uma afirmação impressionista não posso prová-la.

${ }^{4}$ De acordo com Peter Burke, em seu livro: A Escola dos Annales (1929-1989): a Revolução Francesa da Historiografia. Os Annales foi um movimento dividido em três fases: a primeira apresenta a ruptura contra a história tradicional, a história política dos fatos e personagens e a história dos eventos; já na segunda, o movimento aproxima-se da relação estrutura e conjuntura e novos métodos, marcada pela presença de Fernand Braudel; a terceira, traz uma fase marcada pela fragmentação das fontes e objetos de estudos em abordagens múltiplas, que chamamos de Nova História ou História Cultural. 
*Professora Karla Denise, como a senhora avalia a presença do catolicismo na Amazônia brasileira? Existem algumas particularidades para à Amazônia no que tanque ao esboço nacional, se sim, quais?

Karla Denise: Quando falamos de presença temos que pensar em duas vertentes: física e simbólica. Do ponto de vista da presença material da Igreja Católica, é inegável o êxito dessa Religião como instituição e do processo de romanização, cujo enfrentamento com a chamada "fé do povo" sempre foi evidenciada, tanto presente na documentação eclesiástica (Ofícios das Autoridades Eclesiásticas; Livros produzidos pela Diocese do Pará; Jornais Católicos e Liberais; Livros), quanto nos trabalhos acadêmicos que se esforçaram por revolver das letras dos documentos a chamada cultura popular; do ponto de vista simbólico as coisas se misturam e estão confusas um pouco. Há um acúmulo interessante de trabalhos sobre o período colonial e que ressaltou bem as pesquisas sobre as ordens religiosas, congregações e confrarias que atuaram na Amazônia, especialmente a Ordem dos Inacianos até o século XVIII. A documentação produzida, na maior parte das vezes de caráter oficial de ambos poderes (temporal e clerical), menciona um universo popular vibrante, mas que nas pesquisas deve ser garimpado na narrativa eclesiástica. A luta simbólica entre as duas potências ou a interpenetração, dimensão percebida há muito por historiadores e que vêm sendo campo de pesquisa são tópicos em matéria de publicação. Já sai do circuito do eixo temático concernente à História do Pará há um tempo e, por isso, não posso dizer muito sobre as dissertações atuais que devem ter crescido em função do aparecimento dos programas de pós-graduação nos cursos de História das principais universidades da região, mas é sabido que os trabalhos mais antigos foram importantes para trazer a tona o universo religioso seja por que se queria pensar uma História do Catolicismo, seja porque a História Cultural (aqui especificamente da vertente dos Annales em sua História Cultural do Social) levou aos textos cuja preocupação era a cultura popular. Basta procurar na base de algumas dissertações, teses os "velhos" historiadores que ainda vigoram ou para crítica ou para formar o universo factual dos períodos colonial e imperial. Mas, porque meus interesses modificaram não posso dizer muito sobre isso, a não ser que os trabalhos em História até onde pesquisei ainda estavam se conectando com o que se fazia na antropologia, cujo 
casamento redeu muitos frutos. Embora bem distante desse debate acima, não posso deixar de mencionar a contribuição das seguintes obras que me ajudaram a entender muito de história da experiência religiosa na Amazônia: Arthur Cezar Ferreira Reis. A Conquista Espiritual da Amazônia (1942); Arthur Vianna Festas Populares do Pará (1904); José Roberto do Amaral Lapa, Livro da Visitação do Santo Ofício da Inquisição ao Estado do Grão-Pará (1763-1769), de 1978; Raymundo Heraldo Maués Padres, Pajés, Santos e Festas (1995). Atualmente há muitos livros publicados sobre as religiões na Amazônia, alguns resultados de dissertações e teses porém me reservo aqui o silêncio.

* Professora Karla Denise, quais destaques possíveis que a Amazônia possibilita no campo
da pesquisa em religião?

Karla Denise: Acredito que a História Eclesiástica Brasileira e as Histórias das Religiões de modo geral é bem servida de autores no século XX com linhas mais ou menos definidas de abordagem, destacamos aqui Antônio Carlos Villaça, Nilo Pereira, Alceu Amoroso Lima e Dornas Filho (1930-1960), só para citar alguns, e os estudos que emergiram da CEHILA (1973) Riolando Azzi, E. Hoornaert, Enrique Dussel; algumas pesquisas importantes em História Cultural emergiram nas Universidades, uma boa parte desses trabalhos foram resultados de dissertações e teses provenientes da USP, das PUCs e UNICAMP. Ainda em instituições no caso da Amazônia a partir dos anos de 1990 os estudos dissertativos têm tematizado e setorizado mais as os "objetos" de pesquisa em miríades de temas que, muitas vezes, nos impedem de conhecer o montante do trabalho que foi realizado e alguns publicados, porém, essa questão tem relação direta ao avanço dos cursos de pós-graduação na região norte, nem menciono aqui o mar de revistas e coletâneas que desafiam nossa atualização. Ainda acho que os "novos campos" retomam com nova roupagem e conceitos velhos temas: Seminários, Educação, Patrimônio Histórico e Cultural, este último como o tema mais promissor em crescimento. Ao meu ver, o campo que ainda precisa divulgado mais no Brasil é a arqueologia indígena que fica muito retido ao universo específico do corpo científico atuante nos museus da cidade. Contudo, sabe-se que tal área tem mais divulgação, às vezes, que em outros países, refiro-me aqui especificamente aos 
empreendimentos do Museu Emílio Goeldi, instituição fundada em 1871, ápice das pesquisas dos viajantes na região norte, e um dos mais importantes centros de estudos botânicos, zoológicos e pré-históricos da Amazônia até os dias de hoje. Outro campo importante ao meu ver e ainda pouco explorado é o patrimônio religioso, artístico e cultural, além, é claro, do ambiental com suas reservas de material biológico riquíssimo à humanidade. Conheço pouco as iniciativas dessa ordem para cidades como Manaus e Macapá, por isso não posso avançar para mais regiões. Desde 1991, há importante contribuição para o avanço das pesquisas em Patrimônio Religioso e Artístico, os Museus de Arte Sacra, mas foge-me obviamente detalhes do funcionamento no que tange às pesquisas para a imaginária e o conjunto arquitetônico da região.

\footnotetext{
*Professora Karla, segundo dados do censo de 2010 realizados pelo IBGE no que tange aos aspectos religiosos, cerca de $22,2 \%$ da população brasileira declararam-se evangélicos e/ou pentecostais. Qual seu balanço frente a essa onda evangélica que atingiu o Brasil e em especial a Amazônia?
}

Karla Denise: Qualquer declaração oficial sobre crenças no Brasil não deveria sequer ser levada a sério dado o teor sincrético a que historicamente estamos sujeitos, o que vejo com bons olhos. Porém, o que está no IBGE não se pode "negar", é visível a midiatização das Igrejas dessa ordem em nosso país e o domínio de massa que vêm atingindo. No caso da Amazônia, a porta de entrada do Protestantismo bastante estudado pela equipe da CEHILA e por historiadores acadêmicos como David Gueiros Vieira explica-se pelo sincrônico crescimento do terreno fértil em primeiro lugar, semeado por missionários de toda a ordem, e em segundo lugar pela promessa de um cristianismo mais pragmático na resolução de problemas sociais, o que normalmente afasta fiéis da Igreja Católica (por sua ainda persistente elitização na mensagem e na forma litúrgica). Os propagandistas protestantes descem do pedestal e tentam uma maior inserção popular (aliás muitos saem dessa base social) e parecem mais próximos, mais tangíveis aos seus fiéis. Não sou estudiosa do Protestantismo ou mesmo de qualquer corrente evangélica e talvez minha opinião seja mais impressionista que acadêmica, porém, é inegável o discurso verbal e visual que transforma a liturgia em ações pragmáticas (como curas, aconselhamentos, congregações para ajuda 
mútua, representações públicas de possessão, personalismo evangélico e incentivo ao assistencialismo). Essas fórmulas penetram o terreno fértil e pobre da Amazônia, tomando o lugar do poder público ausente e oferecendo benefícios sociais tangíveis, além dos bônus pos-mortem. As Igreja Protestantes (Evangélicas) juntaram a máquina litúrgica, o bom discurso popular à salvação não só no além, mas aqui e agora, o que seduz imensamente um conjunto de pessoas carentes em todos os sentidos.

*Professora Karla, segundo dados do Ministério dos Direitos Humanos nos revelaram que a cada 15 horas um brasileiro é vítima de intolerância religiosa. Dentre as religiões que são alvo de atitudes intolerantes destacam-se as religiões de matrizes africana. Como a senhora avalia as políticas públicas direcionadas a sociedade civil e ao povo de terreiro no que diz respeito ao combate e conscientização da população sobre o crime de intolerância religiosa e racismo religioso?

Karla Denise: Bem, historicamente os cultos de matrizes afro-indígenas, esotéricos, wicca, ocultistas e mesmo espiritismo desde o século XIX, precisamente na virada para o século XX, enfrentam a inserção e o processo de aceitação. A Constituição de 1824, outorgada por D. Pedro I, foi um ponta pé para a direção dessa questão que obviamente não se resolve nas letras, o seu artigo $5^{\circ}$. ajuda a compreender um pouco o processo por que tais questões vêm se arrastando desde aquela época: “A Religião Católica Apostólica Romana continuará a ser a religião do Império. Todas as outras religiões serão permitidas com seu culto doméstico, ou particular, em casas para isso destinadas, sem forma alguma exterior de templo." (Trecho da Constituição Outorgada por D. Pedro I em 1825). Vejamos que com a Independência do Brasil o Catolicismo ocupou o centro demonstrável de culto da sociedade brasileira e já nas letras temporais havia a proibição do culto exterior de qualquer credo que não fosse o Católico. Porém, também havia no Brasil inúmeras culturas que emergiam mesmo sob os olhares do poder oficial e nunca deixaram de existir, isto porque os indivíduos resistiram ou misturavam suas crenças aos cultos ensinados especificamente pelas ordens ou por párocos ou subsistiram em suas próprias tradições. Isso só não explica obviamente a intolerância religiosa, com o avanço no século $\mathrm{XX}$ das igrejas evangélicas e uma transferência de fiéis para as mesmas, a sobrevivência do Catolicismo continuou a depender 
da ação sempre efetiva de bispos e da rede católica em todo o país sempre subsidiada pelos governos locais, nacionais e mesmo federal, além da fertilização das mentes ao longo de séculos. Uma informação interessante aos pesquisadores é a base das leis no Brasil após o período republicano que surgiu como paradoxal escudo do Catolicismo contra outras formas de crenças: espiritismo, candomblé, pajelança, práticas de magia, por exemplo. Refiro-me aqui ao código penal de 1890 nos seus artigos: 156, 157 e 158 que proibiam a manifestação dessas formas religiosas. Não posso obviamente avançar em tal exposição sem pontuar o crescimento das Igreja Evangélicas, nas últimas décadas, inclusive com a aquisição de cargos políticos e mesmo com a compra de mídia de massa (canais televisivos). À despeito das inúmeras diferenças entre as igrejas evangélicas de modo geral e até mesmo do ponto de vista doutrinário e condutor do evangelho, a direção agora seria de um lado o histórico Catolicismo e as novas correntes pentecostais e evangélicas em todo o país. O discurso para com os outros credos não só ficou mais evidente como influi diretamente na ação de intolerâncias visíveis. As frentes católicas e evangélicas são distintas e rivais obviamente, porém, de modo bifurcado essas duas forças religiosas possuem agentes contrários à liberdade de consciência e ao culto afro-indígena e neo-pagão de modo geral. Um caso que posso citar que comoveu a opinião pública, por exemplo, e a comunidade católica do país foi o do "chute" da imagem de Nossa Senhora Aparecida por um Pastor da Igreja Universal do Reino de Deus em um programa de emissora popular no Brasil, no ano de 1995, quando da famosa festa nacional dessa Santa. Casos de queima de imagens em terreiros de Candomblé têm sido cada mais noticiados, porém, quando a questão escapa para a violência física é porque a situação realmente perdeu totalmente o controle.

*Professora Karla, vivemos em um país laico? Como a senhora compreende a laicidade brasileira?

Karla Denise: Acredito que desde a Proclamação da República, 1889, o Brasil optou por um Estado que se conduz, pelo menos do ponto de vista teórico, por leis e sistemas dessacralizados, embora muitos tribunais no país sustentam crucifixos nas paredes e fazem juramento usando a Bíblia. Ministro aula em uma universidade aonde há uma capela católica 
ocupando uma das áreas mais nobres do campus. Porém, como já afirmei, a Nação Brasileira não é laica em sua maioria. Nem sempre as determinações do Estado condizem com os anseios populares (da Nação) e a Religião sempre teve seu papel em atender aonde o poder público não está ou, se está, não consegue diminuir o sofrimento das pessoas, isto implica dizer que a busca por respostas mesmo em um ambiente considerado laico permanece à despeito do Estado. Contudo, não é só o sofrimento material (uma sociedade empobrecida) que fez crescer e manter os laços religiosos e a crença em algo, isso porque mesmo em países considerados avançados do ponto de vista econômico, não deixaram de ter um sistema de crenças vigoroso e crescente. Minha especialidade não é a História Religiosa Contemporânea, mas sobre isso tenho lido e cogitado. A chamada promessa de dessacralização desde o avanço dos sistemas econômicos e técnicos mais modernos não se fez efetiva. A América Latina como um todo, como os próprios analistas do CELAM e da CEHILA têm umas das marcas de maior crescimento em religiões de doutrina (Evangélicos), mas o sincretismo ainda é a sua característica mesmo em regiões onde tais Igrejas e a já tradicional Católica foi mais efetiva em matéria de conquista. Não importa aqui ao meu ver como cada corrente teórica considera o que seja sincretismo, isto por que há diversas, porém, a mistura é um efeito das próprias resistências de décadas às chamadas religiões consagradas. Outro elemento que acredito ser pertinente pensar é a própria vigorosa crença, que se espalha, se interpenetra e se cruza, tomando caminhos interessantes e novos, dado o próprio movimento das necessidades dos grupos e que não dependem das máquinas institucionais atuantes.

*Professora Karla, quais suas impressões sobre o Ensino Religioso nas escolas públicas brasileiras?

Karla Denise: Recentemente houve um debate sobre a volta do Ensino Religioso nas Escolas Públicas, não sei ao certo o teor do projeto, porém, acho importante que o mesmo venha acompanhado, se assim for o que a sociedade deseja, de uma educação infanto-juvenil com vistas ao respeito não só a religião e religiosidade de todos, mas ao ser humano, um 
senso ético de convivência entre as pessoas e isenção por parte dos governantes quando se tratar dessa matéria em leis, projetos e qualquer outro tipo de ação pública e gestão pública. Um amigo me disse, mas o Brasil tem Estado Laico como e para quê ensino religioso, para tomar lugar das disciplinas técnicas? Pensei sobre o que disse e apenas afirmei que o Estado era laico, mas a nação não, o que implica dizer que as formas religiosas ainda são elementos importantes na condução de vida das pessoas e, discutir o respeito aos sistemas de crenças era um caminho para pensar em respeito mútuo, seja em matéria religiosa, seja qualquer outra questão. O grande problema ao meu ver é um projeto como esse nas mãos de tendenciosos a uma única corrente religiosa, o que seria catastrófico para a implementação pedagógica e até antidemocrático, e se for nessas condições o ideal e a retirada do Ensino Religioso para que os jovens não cresçam com via de mão única, acirrando assim as diferenças culturais e aumentando a violência nessa matéria.

* Professora Karla, ainda sobre a Amazônia, como se deu este processo civilizador cristão para com a sociedade amazonida?

Karla Denise: Em vários autores como Arthur C. Ferreira Reis, Ernesto Cruz, Antônio Ladislau M. Baena; Vicente Salles, Heraldo Maués, Anaíza Vergolino e Silva, e os consagrados textos do português João Lúcio de Azevedo a quem admiro pela garra e amor pela leitura, Serafim Soares Leite dentre muitos outros que estudei é possível encontrar longa exploração que esclarece o processo de conquista da Amazônia. Realizei estudos sobre o processo de romanização de modo mais específico e é pertinente dizer que a Igreja contou com os Jesuítas e com os Franciscanos no período colonial e quando os Jesuítas foram expulsos à época do Marquês ilustrado (Pombal) já havia um terreno plantado pelo Catolicismo. Claro que essa ausência jesuíta causou grandes problemas à organização da Igreja e mesmo do poder civil, porém, contornado com a presença sempre marcante da Igreja secular e das famílias católicas, assim como as Ordens Terceiras, Confrarias e outras organizações. A maioria destes autores nos ajuda a compreender o estabelecimento da Igreja na região Amazônica, porém suas escalas são seculares, alguns livros aqui mencionados que trataram de temas como o negro no Pará ou mesmo as práticas luso-afro-indígenas formam 
a cortina necessária para entender que na superfície o projeto católico teria se projetado a todos os outros sistemas de crenças, mas como já mencionei antes, as tensões e as lutas entre as várias formas religiosas foram alvo de pesquisas e esclarecem que o "projeto civilizador" é complexo e não deve ser tratado com qualquer resposta definida. $\mathrm{O}$ fato é que tentar mapear até onde vai a influência da Igreja Católica e das formas civilizacionais na Amazônia me parece um falso problema, dada a interpenetração das culturas que ainda hoje desafiam a coerência buscada pelos historiadores. Prefiro dizer que na casca a civilização existiu, mas no fruto ela não penetrou de um modo a levar ao desaparecimento das populações tradicionais e do conhecimento rico que tais grupos deixaram. Hoje tenho incentivado mais as pesquisas dos saberes tradicionais como o conhecimento das ervas medicinais aplicadas à cura; a relação entre uso de ervas e religiosidade; os processos de catalogação das plantas, da apropriação científica das mesmas e de todas as boas práticas antigas, das práticas ocultistas e mágicas (cartomancia, necromancia e toda a espécie de culto secreto) que só não foram ainda perdidas em função de sensíveis trabalhos de recuperação e divulgação.

* Professora Karla, qual seu balanço do papado do Papa Francisco e sua política religiosa para Amazônia?

Karla Denise: De certo, o que vou dizer talvez já esteja mesmo sendo visualizado no senso comum, um "Francisco" no Vaticano é paradoxal, no entanto toda a observação deve ser entendida em um contexto no qual a Igreja, como já se sabe, vem perdendo a cada ano terreno para outras formas de pensamento e templos. O papel do PP nesses tempos é o de integração, e Francisco realiza bem o papel, mesmo que para isso tenha que se indispor com uma ala conservadora de Roma que cobra ações endógenas em um PP cuja perspectiva é orientada no discurso à sociedade dos pobres e dos excluídos. Realmente não tenho acompanhado as realizações ou pronunciamentos para a Amazônia, porém, o discurso de inclusão e de perdão juntos parece elevar Francisco à condição de um dos papas mais populares da História da Igreja, perdendo só para João Paulo II. Em 2013, o Papa esteve no Brasil e trouxe alguns pronunciamentos sobre a Amazônia, entre os quais estava a ideia de preservação do meio ambiente como o slogan "Paraiso do Mundo". Tendo estado junto aos 
índios pela "proteção da floresta", Francisco na sua Encíclica Laudato Si (2015) reforça os resultados já conhecidos da comunidade científica sobre as mudanças climáticas e a importância da Amazônia para o mundo e da necessidade de ações urgentes de preservação. O outro problema atacado nesta visita foi o celibato eclesiástico que, em alguns lugares, não vingou produzindo um conjunto de problemas para a Igreja. Para alguns, a política do pontifex tem atacado as questões do mundo atual e os principais problemas históricos da Igreja: o celibato, a vocação e o divórcio, além de enfrentar as denúncias "cara a cara" relativas à pedofilia, que vinha se arrastando em muitos papados e que só agora parece ter sacudido a poeira da Santa Sé. No caso específico da Amazônia ainda não sabemos o resultado efetivo do "projeto piloto" para a superação do celibato eclesiástico que o Papa teria aventado com grande cuidado quando fez a visita. Não sei ao certo se tais iniciativas realmente serão realizadas em alguns decênios, mas o fato de haver debate sobre as mesmas no âmago da Igreja cria a esperança de mudanças na condução do pontificado. Ter a atenção do Vaticano voltada para a Amazônia é um caminho importante para sensibilizar católicos do mundo inteiro.

\section{Referências bibliográficas publicadas pela Karla Denise:}

MARTINS, K. D. . A ? civilização cristã ? como projeto católico para a sociedade amazônica: D. Macedo Costa e seus interlocutores no oitocentos. Revista Tempo Amazônico , v. 2, p. 141-169, 2015. MARTINS, K. D. . Dai a César o que é de César e a Deus o que é de Deus, relações entre a Igreja e o Estado no Pará oitocentista. Revista de História Regional , v. 13, p. 70-103, 2009.

MARTINS, K. D. . O Ensino Religioso no Brasil: considerações sobre o processo de cristianização. Revista de Ciências Humanas (Viçosa), v. 9, p. 137-148, 2010.

OLIVEIRA, Luciano Conrado ; MARTINS, K. D. . O ultramontanismo em Minas Gerais e outras regiões do Brasil. Revista de Ciências Humanas (Viçosa), v. 11, p. 259-269, 2011.

TEIXEIRA, F. A. F. ; MARTINS, K. D. . A preservação e divulgação do patrimônio histórico da RPPN - Santuário do Caraça. ELO - Diálogo em Extensão , v. 02, p. www.elo.ufv.br, 2013.

TEIXEIRA, F. V. ; FERNANDES, T. C. ; MARTINS, K. D. . A atuação lazarista na Diocese de Mariana (1820-1875). Revista de Ciências Humanas , v. 15, p. 242-265, 2015. 